Revue d'histoire de l'Amérique française

REYUE D.HISTOIRE DE L'AMÉRIQUE FRANÇAISE

\title{
BUCHIGNANI, Norman, Doreen M. INDRA et Ram SRIVASTIVA, Continuous Journey - A Social History of South Asians in Canada. Toronto, McClelland \& Stewart, 1985. 250 p. 12,95 \$.
}

\section{Richard Jones}

Volume 39, numéro 4, printemps 1986

URI : https://id.erudit.org/iderudit/304408ar

DOI : https://doi.org/10.7202/304408ar

Aller au sommaire du numéro

Éditeur(s)

Institut d'histoire de l'Amérique française

ISSN

0035-2357 (imprimé)

1492-1383 (numérique)

Découvrir la revue

Citer ce compte rendu

Jones, R. (1986). Compte rendu de [BUCHIGNANI, Norman, Doreen M. INDRA et Ram SRIVASTIVA, Continuous Journey - A Social History of South Asians in Canada. Toronto, McClelland \& Stewart, 1985. 250 p. 12,95 \$.] Revue d'histoire de l'Amérique française, 39(4), 602-604. https://doi.org/10.7202/304408ar d'utilisation que vous pouvez consulter en ligne.

https://apropos.erudit.org/fr/usagers/politique-dutilisation/ 
BUCHIGNANI, Norman, Doreen M. INDRA et Ram SRIVASTIVA, Continuous Journey - A Social History of South Asians in Canada. Toronto, McClelland \& Stewart, 1985.250 p. 12,95\$

Au début des années 1970, les historiens canadiens ont finalement découvert les groupes ethniques ou, comme nous les appelons un peu pudiquement au Québec, les «communautés culturelles». Certes, le Canada accueillait (pas toujours très chaleureusement), depuis la fin du siècle dernier, un grand nombre d'immigrants ni britanniques ni français. Mais les Canadiens anglophones estimaient que le sort «normal» de ces nouveaux venus devait être une assimilation rapide. Quant aux Canadiens francophones, préoccupés de la survivance de leur propre groupe, ils réagissaient le plus souvent avec méfiance. Faut-il rappeler aussi que tous les historiens appartenaient à l'un ou l'autre des «deux peuples fondateurs»?

Aux années 1960, alors que les Canadiens français revendiquent vivement l'égalité avec les anglophones, les «autres» Canadiens s'estiment ignorés. La Commission royale d'enquête sur le bilinguisme et le biculturalisme souhaite des mesures pour conserver la diversité culturelle. Finalement, en octobre 1971, le premier ministre Trudeau déclare que le gouvernement optera pour «une politique multiculturelle dans un cadre bilingue». Le Secrétariat d'Etat, chargé de favoriser le multiculturalisme, prendra une foule d'initiatives dont 
celle de commanditer des études sur les groupes ethniques. A ce jour, une douzaine d'histoires ethniques ont vu le jour. Ce livre sur les Indiens asiatiques en est une.

Les auteurs, tous deux anthropologues à l'Université de Lethbridge, ont divisé leur ouvrage en trois parties chronologiques. La première période couvre les années 1902-1918: à ce moment, une petite colonie indienne s'établit sur les bords du Pacifique. A peu près tous les immigrants arrivent en l'espace de quelques mois (1906-08), à peu près tous sont Sikhs, et tous, comme les Orientaux installés en Colombie britannique, sont victimes d'innombrables mesures discriminatoires.

De 1918 à 1947, la communauté est menacée de disparition. En l'absence de sang neuf, la population vieillit et diminue à environ 1000 personnes. Même si ceux qui restent sont plus prospères, l'hostilité des Canadiens demeure vive.

Depuis la guerre, cependant, une véritable révolution s'amorce. La discrimination légale cesse et les Asiatiques obtiennent le droit de vote. L'immigration reprend, d'abord lentement en raison des quotas infimes imposés par le gouvernement canadien, puis, dès les années 1960 alors que le Canada élimine la discrimination dans sa politique d'immigration, beaucoup plus vigoureusement. Si le Canada compte moins de 7000 Indo-Asiatiques en 1961, on peut en dénombrer plus de 300000 aujourd'hui. Cette nouvelle population est d'une étonnante diversité à tous les égards. Elle s'installe davantage en Ontario mais toutes les villes canadiennes en comptent des regroupements. Elle s'intègre rapidement dans la vie économique canadienne, mais en même temps elle établit des réseaux communautaires informels et institutionnels. Enfin, surtout vers la fin des années 1970, elle est victime de préjugés qui, d'après les auteurs, s'atténuent même s'ils persistent toujours.

A la lecture de cet ouvrage, il est loisible de se demander si on peut qualifier les Indiens asiatiques de «groupe». D'autres études dans cette série ont porté sur les Grecs, les Polonais, les Hongrois et les Estoniens: il s'agitlà, bien sûr, de groupes où il est relativement facile de cerner une identité commune. Mais les Indiens asiatiques? Ils arrivent de plusieurs pays, tels l'Inde et le Pakistan, évidemment, mais aussi l'Ouganda, les Iles Fidji, l'Ile Maurice et la Guyane. Ils sont très différents les uns des autres sur les plans linguistique, religieux et culturel. Ils pratiquent toute la gamme des occupations. En dehors du groupe restreint (défini par la langue, l'origine ethnoculturelle ou la religion), ils ont plus de relations avec les Canadiens qu'avec d'autres Indo-asiatiques. Comme l'affirment les auteurs: «La croyance commune que les Indo-asiatiques constituent une communauté homogène au Canada est entièrement fausse.» (p. 127)

Peut-on alors parler d'un groupe? Oui, le prétendent néanmoins les auteurs. Ce qui compte c'est l'identité dont plusieurs traits permettent, d'après eux, de parler d'une «unité dans la diversité». Mais quels sont ces traits? Après quelques vaillantes tentatives d'en distinguer quelques-uns, les auteurs concluent qu'ils «se sentent Indo-asiatiques... L'immigration a fait d'eux un groupe minoritaire et ils savent fort bien que d'autres Canadiens les perçoivent comme ethniquement et physiquement différents» (p. 163). En d'autres termes, leur unité serait fonction, en grande partie, de la perception des Canadiens; les préjugés des 
Canadiens à leur endroit ne font que renforcer cette identité commune. Si tel est vraiment le cas, on peut bien se demander ce que l'avenir leur réserve.

Que deviendra, en effet, ce groupe-qui-n'en-est-pas-un? Les auteurs semblent déchirés entre leurs espoirs et la réalité qu'ils observent. D'une part, ils déclarent que les Indo-Asiatiques sont très conscients de leur ethnicité et ils parlent d'un «ajout important à la mosaïque culturelle canadienne» (p. 233). Mais d'autre part, ils soulignent leur «rapide et dramatique» intégration. "Seules une petite proportion [de leurs] pratiques culturelles ont survécu au processus d'installation», avouent-ils. Pour ce qui est de la deuxième génération, majoritairement encore très jeune, elle «subit une assimilation et une acculturation massives» (p. 158). Sauf chez les Sikhs, les enfants maîtrisent peu la langue d'origine. Leur vie culturelle a été canadianisée. Vont-ils avoir tendance à se marier à l'intérieur du groupe? Et qu'est-ce que les membres de la troisième génération conserveront de l'identité, surtout si l'attitude plus positive des Canadiens ne les force plus à se percevoir comme différents? Un peu de musique, de danses folkloriques, de nourriture typique?

Cette étude pose donc des questions auxquelles on ne peut, pour le moment, répondre. Mais elle a le grand mérite de présenter, d'une façon assez objective et en utilisant une abondance de sources, l'expérience d'un «groupe» que les Canadiens d'origine connaissent fort peu.

Département d'histoire

Université Laval

RICHARD JONES 